\title{
Dysregulation of microRNAs and their association in the pathogenesis of $\mathrm{T}$-cell lymphoma/leukemias
}

\author{
Sho Ikeda $\cdot$ Hiroyuki Tagawa
}

Received: 26 December 2013/Revised: 19 January 2014/Accepted: 4 February 2014/Published online: 25 February 2014

(c) The Japanese Society of Hematology 2014

\begin{abstract}
MicroRNAs (miRNAs) are non-coding regulatory RNAs consisting of 20-24 nucleotides. Over 4,500 miRNAs have been identified in humans, and it is known that nearly all human protein-encoding genes can be controlled by miRNAs in both healthy and malignant cells. Abnormal miRNA expression is known to occur in many cancers, including in malignant lymphomas (MLs). Detailed genome-wide miRNA expression analysis has been performed in various ML subtypes, and these analyses have led to the discovery of subtype-specific miRNA alterations. Actually, in B-cell lymphomas, several miRNAs have been used as prognostic markers, and their targets are for new agents for ML therapy. Successful studies for delineating miRNA functions in B-cell lymphomas lead us to hypothesize that miRNA dysregulation may also be deeply associated with the pathogenesis of T-cell lymphomas. Indeed, studies for delineating essential miRNAs have been conduced against comparatively well-defined T-cell lymphoma entities. In this review, we describe several key miRNAs and their targets in distinct T-cell lymphoma subsets and their roles in their pathogenesis, studies of which will lead to new therapeutic strategies against T-cell lymphomas.
\end{abstract}

Keywords MicroRNA - T-cell lymphoma/leukemia

S. Ikeda $\cdot$ H. Tagawa $(\bowtie)$

Department of Hematology, Nephrology, and Rheumatology, Akita University Graduate School of Medicine, 1-1-1 Hondo, Akita 0108543, Japan

e-mail: htagawa0279jp@yahoo.co.jp;

htagawa@doc.med.akita-u.ac.jp

\section{Introduction}

MicroRNAs (miRNAs) are non-coding regulatory RNAs consisting of 20-24 nucleotides [1]. miRNAs act by controlling the translation of proteins from mRNAs, and by doing so play a crucial role in normal cell differentiation and proliferation [1]. miRNAs were first identified by Ambros and coworkers in the nematode Caenorhabditis elegans (1993), who showed that the miRNA lin-4 plays an important role in cellular differentiation through inhibition of lin-14 expression [2]. Thereafter, Ruvkun's group (2000) identified let-7, another lin-4-like small non-coding RNA, in worms [3], and Bartel's and Tuschl's labs (2001) independently cloned and identified miRNAs from worms, flies, and humans $[4,5]$. At present, over 4,500 miRNAs have been identified in humans, and it is known that nearly all human protein-encoding genes can be controlled by miRNAs in both healthy and malignant cells. Abnormal expression of miRNA is now known to occur in many cancers, including malignant lymphomas (MLs) [6-14].

Malignant lymphoma is classified into Hodgkin's or non-Hodgkin's lymphoma. On the basis of normal correspondence lymphoid cells, non-Hodgkin's lymphoma is further classified into B- and T/NK-cell lymphomas. These can also be divided into a number of subtypes; for instance, B-cell lymphoma can be classified into diffuse large B-cell lymphoma, Burkitt's lymphoma, mantle cell lymphoma, follicular lymphoma, MALT (mucosa-associated lymphoid tissue) lymphoma, and other subtypes $[15,16]$. These classifications are usually made on the basis of subtypespecific translocation or origin of their normal parts. In B-cell lymphomas, molecular-based classifications of the subtypes have been successfully conducted, leading to the development of understanding of their pathogenesis. Subtype-based miRNA classification has also been 
successfully conducted in B-cell lymphomas [11-14]. In T-cell lymphomas, however, attempts at translocation- or molecular-based classification have been unsuccessful to date, and as a result, understanding of molecular-based pathogenesis of T-cell lymphoma has been insufficiently established. This suggests that other classification strategies, such as miRNA expression analysis, may be additionally useful.

miRNA dysregulation may be associated with pathogenesis or disease progression in T-cell lymphoma. Recent studies have revealed the deregulation of key miRNAs and their targets in well-defined T-cell lymphomas, such as anaplastic lymphoma kinase (ALK)-positive anaplastic large cell lymphoma. In this review, we discuss the association between miRNA and normal T-cell differentiation, summarize recent findings on the roles of miRNA in T-cell lymphoma pathogenesis, and provide perspectives into the use of new candidate drugs for treating tumor entities. Further, we propose some problems confronting miRNA studies against MLs, which remain to be addressed in future studies.

\section{MicroRNA functions in normal T-cell differentiation}

Recent studies have shown that several miRNAs are deeply associated with lymphoid development and maturation. Before we describe miRNA functions in T-cell lymphomas, we should begin by outlining miRNA function in normal T-cell differentiation, as dysregulation of miRNAs can induce tumorigenesis in otherwise normal $\mathrm{T}$ cells.

T-cell development in the thymus is controlled by a complex but precise signal network. Developmental stages are classified as double-negative (DN), double-positive (DP), and single-positive (SP) with respect to $\mathrm{CD}^{+}$and/or $\mathrm{CD} 8^{+} \mathrm{T}$ cells. $\mathrm{T}$-cell receptor (TCR) rearrangement occurs during the transition from DN to DP, or from DP to SP. T cells are selected by specificity of antigen specification, which is defined by the TCR variable region.

Chen and coworkers [17] first reported a miRNA association in hematopoiesis. They found that, as miR-181, miR-223, and miR-142s are highly expressed in murine hematopoietic cells, enforced expression of miR-223 and miR-142s led hematopoietic stem cells to mature into the T-cell lineage, while miR-181 expression led to B-cell maturation. These miRNAs are now recognized for their important roles in hematopoiesis. miR-150 also plays a crucial role in lymphoid cell development. Monticelli and coworkers [18] reported that, in a mouse model, although miR-150 expression was not detected in pro T- or B-cells, the expression did appear, and became stronger with lymphocyte maturation. However, in mature $\mathrm{T}$ cells, the expression is lower in naïve $\mathrm{T}$ cells to $\mathrm{T}_{\mathrm{H}} 1$ or $\mathrm{T}_{\mathrm{H}} 2$ cells. In addition, $\mathrm{CD}^{+}{ }^{+} \mathrm{T}$ helper cells are divided into $\mathrm{T}_{\mathrm{H}} 1, \mathrm{~T}_{\mathrm{H}} 2$, $\mathrm{T}_{\mathrm{H}} 17$, and $\mathrm{T}_{\mathrm{H}} 22$ subsets. Zhou and coworkers [19] also focused on miR-150, which usually shows high expression in spleen and thymus. They demonstrated that miR-150 inhibits pro-B to pre-B development. In other work the same year, Xiao and coworkers [20] reported that miR-150 regulates B-cell maturation by targeting a transcription factor, c-Myb. There is a deep relationship between miR150 and c-Myb in T-cell development, as c-Myb is highly activated in DN3 $\left(\mathrm{CD} 44^{-} / \mathrm{CD} 25^{+}\right)$and DP or SP, and its activation is necessary for their development [21, 22]. Recently, a novel target of miR-150 during T-cell development has been reported. Using whole-genome miRNA analysis against DP or SP of $\mathrm{CD} 4^{+}$or $\mathrm{CD}^{+}$, Ghisi and coworkers [23] identified several miRNAs that may be associated with the transition from DP to SP. They focused on miR-150, which is highly expressed in the SP phase, and found that miR-150 controls Notch3, and that Notch3 deregulation may induce T-cell malignancies [24].

Other miRNAs associated with T-cell differentiation include miR-181a and miR-155. Li and coworkers [25] demonstrated that miR-181a is highly expressed in earlier phases of T-cell maturation, such as DN (especially DN3) or DP, and that its expression decreases after the SP phase through the regulation of dual-specificity phosphatase (DUSP) $5 / 6$, which potentially inhibits extracellular signal-regulated kinase (ERK) signaling or a tyrosine phosphatase, SHP-1/2. Neilson and coworkers [26] also reported that miR-181a negatively regulates $\mathrm{Bcl} 2$, CD69, or TCR during the DP phase. These reports demonstrate that miR-181a plays crucial roles in T-cell sensitivity and selection. As for miR-155, Thai and coworkers [27] demonstrated that knockdown of miR-155 leads $\mathrm{T}$ cells to differentiate into the $\mathrm{T}_{\mathrm{H}} 2$ type with up-regulation of IL-4 and down-regulation of interferon- $\gamma($ IFN- $\gamma)$. At the same time, Rodriguez and coworkers [28] also showed that miR-155 targets c-Maf, which is expressed in $\mathrm{T}_{\mathrm{H}} 2$ $\mathrm{CD} 4{ }^{+} \mathrm{T}$ cells, leading to down-regulation of IL-4. These findings suggest that miR-155 expression regulates $\mathrm{T}$-cell development, especially differentiation into $\mathrm{T}_{\mathrm{H}} 1 \mathrm{CD}^{+} \mathrm{T}$ cells.

These studies show that a number of miRNAs are deeply associated with the control of important signaling pathways in T-cell development and maturation. Interestingly, these reports reveal that a single miRNA (e.g., miR-150) potentially possesses diverse functions by regulating various targets in different stage of cell differentiation, suggesting that a miRNA may target the translation of various proteins in different cancer cell lineage, including malignant lymphomas. These reports also suggest that miRNA 
dysregulations associated with T-cell development may show strong correlations with T-cell malignancies.

\section{miRNA expression analysis against $\mathrm{T}$-cell lymphomas}

In the WHO (World Health Organization) classification, T-cell lymphomas are histopathologically heterogeneous and can be classified into $\sim 20$ subtypes [29]. T-cell lymphomas are subdivided in three major subgroups, (A) cutaneous [mycosis fungoides (MF), Sézary syndrome (SzS), primary cutaneous CD30-positive T-cell lymphoproliferative disorders and primary cutaneous T-cell lymphoma (CTCL), etc.], (B) nodal [peripheral T-cell lymphoma (PTCL), PTCL-not otherwise specified (PTCL-NOS), anaplastic large cell lymphoma (ALCL), angioimmunoblastic T-cell lymphoma (AITL), and adult T-cell leukemia/lymphoma (ATLL)], and (C) extranodal. With the exception of ALK-positive $\left(\mathrm{ALK}^{+}\right)$ALCL, subtype-specific translocation has not been observed in T-cell lymphomas. Therefore, the development of molecular-based therapeutic strategies for T-cell lymphoma remains insufficient, particularly when compared with those for B-cell lymphoma.

Other than specific translocations, such as $t(2 ; 5)$ (p23; $\mathrm{q35}$ ), as seen in $\mathrm{ALK}^{+} \mathrm{ALCL}$, there is no subtypespecific translocation in T-cell lymphomas associated with a known miRNA alteration. Whole-genome miRNA expression analyses of malignant lymphomas are the subject of international research [30-32]; however, efforts at unsupervised miRNA expression analysis, including those in various T-cell lymphoma subtypes, remain unsuccessful. Although the aberrant expression of many miRNAs has been identified in T-cell lymphomas, when one compares miRNA expression of tumor samples with normal correspondence cells, there is a poor overlap among differentially expressed miRNAs identified by multiple miRNA platforms. We thus must further validate such findings to examine whether identified miRNAs are in fact functional in the regulation of genes associated with lymphomagenesis. To identify the roles of miRNA deregulation in lymphomagenesis, studies in combination with whole-genome gene expression analysis may be useful. In this vein, Suzuki and coworkers [33] recently developed a novel method for detecting relationships between miRNAs and their candidate targets, which they call GSEA-FAME analysis (GFA). This method was also useful for detecting essential and novel therapeutic targets of unclassified T-cell lymphomas [34].

In the following sections, we focus on miRNA dysregulation and its function in (a) CTCL (SzS, MF), (b) nodal peripheral T-cell lymphomas [(1) ALCL, (2) ATLL, (3) PTCL-NOS], and (c) extranodal (e.g., NK/T-cell lymphoma, nasal type). Deregulated miRNAs in T/NK-cell lymphomas are summarized in Table 1.
Table 1 Validated miRNA targets and regulation factors in T/NKcell lymphoma/leukemias

\begin{tabular}{|c|c|c|c|c|}
\hline $\begin{array}{l}\text { ML/ } \\
\text { microRNA }\end{array}$ & Up-stream & $\begin{array}{l}\text { Up/ } \\
\text { down }\end{array}$ & Target(s) & References \\
\hline \multicolumn{5}{|l|}{ CTCL } \\
\hline miR-155 & $\begin{array}{r}\text { IL-2R } \beta \gamma / \\
\text { STAT5 }\end{array}$ & Up & ND & [41] \\
\hline miR-21 & $\begin{array}{l}\text { IL-21/ } \\
\text { STAT3 }\end{array}$ & Up & ND & [42] \\
\hline miR-342 & miR-199* & Down & ND & {$[36,43]$} \\
\hline miR-150 & c-Myc? & Down & CCR6, IL-22 & [45] \\
\hline miR-125b-5p & c-Myc & Down & MAD4 & [92] \\
\hline \multicolumn{5}{|l|}{${\mathrm{ALCL} \mathrm{ALK}^{+}}^{+}$} \\
\hline miR-101 & ND & Down & mTOR & [55] \\
\hline \multirow[t]{2}{*}{$\operatorname{miR}-135 b$} & ALK/STAT3 & Up & $\begin{array}{l}\text { FOXO1, STAT6, } \\
\text { GATA3 }\end{array}$ & [65] \\
\hline & & & PPP2R5C/p53 & [34] \\
\hline miR-17-92 & ALK/STAT3 & Up & Bim, TGF $\beta$ RII & [63] \\
\hline miR-21 & ALK/STAT3 & Down & DNMT1 & [66] \\
\hline miR-219 & ALK/STAT3 & Down & ICOS & [67] \\
\hline miR-26a & ALK/STAT3 & Down & iNOS/NO & [68] \\
\hline miR-29a & ALK/STAT3 & Down & MCL-1 & [69] \\
\hline miR-16 & ALK, HIF $1 \alpha$ & Down & VEGF & [70] \\
\hline \multicolumn{5}{|l|}{ ALCL $\mathrm{ALK}^{-}$} \\
\hline miR-29a & Translocation & Up & DUSP22 & [71] \\
\hline \multicolumn{5}{|l|}{ ATLL } \\
\hline miR-101 & ND & Down & $\mathrm{EZH} 2$ & [77] \\
\hline miR-128a & ND & Down & $\mathrm{EZH} 2$ & [77] \\
\hline miR-31 & $\mathrm{EZH} 2$ & Down & NIK/NFкB & [78] \\
\hline \multicolumn{5}{|l|}{ PTCL-NOS } \\
\hline miR-187 & ND & Up & $\begin{array}{l}\text { Dab2/Grb2/ERK/ } \\
\text { AKT/MYC }\end{array}$ & [82] \\
\hline \multicolumn{5}{|l|}{$\mathrm{NK} / \mathrm{T}$} \\
\hline miR-21 & EBV? & Up & PTEN/PIP3/AKT & [80] \\
\hline miR-155 & EBV? & Up & SHIP1/PIP3/AKT & [80] \\
\hline miR-150 & c-Myc? & Down & AKT2, DKC1 & [44] \\
\hline
\end{tabular}

$M L$ malignant lymphoma, $A L C L$ anaplastic large cell lymphoma, $A L K$ anaplastic lymphoma kinase, $C T C L$ cutaneous T-cell lymphoma, ATLL adult T-cell leukemia/lymphoma, $N K / T$ NK/T-cell leukemia/lymphoma, $E B V$ Epstein-Barr virus, PTCL-NOS peripheral T-cell lymphoma, not otherwise specified, $N D$ not determined

\section{Subtype-specific miRNA dysregulation in T-cell lymphoma/leukemias}

(a) CTCL (Figs. 1, 2)

CTCL includes several subtypes, such as MF, SzS, cutaneous-ALCL and others. MF follows an indolent clinical course and accounts for nearly $50 \%$ of all primary cutaneous lymphomas $[29,35]$, whereas $\mathrm{SzS}(5 \%)$ shows an 
aggressive clinical course accompanied with the presence of clonally related neoplastic $\mathrm{T}$ cells with cerebriform nuclei (Sézary cells) in skin, lymph nodes, and peripheral blood. Histological features of SzS are similar to those of $\mathrm{MF}$, and commonly derived from skin-forming $\mathrm{CD} 4^{+} \mathrm{T}$

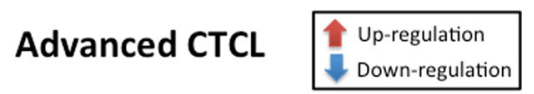

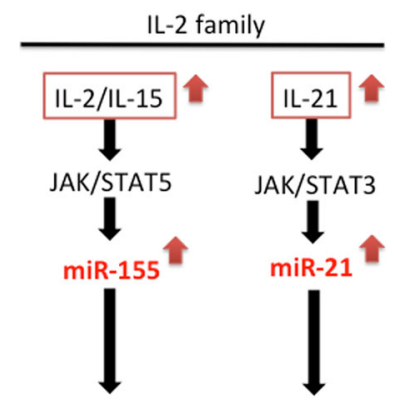

proliferation anti-apoptosis

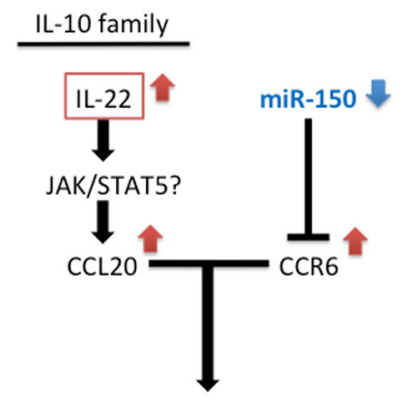

migration

Fig. 1 IL-2 or IL-10 families/JAK/STAT pathways and association of miRNAs in CTCL cells, suggesting that advanced MF and SzS are identical tumor entities. The remaining $\sim 30 \%$ of CTCL represents primary cutaneous CD30-positive T-cell lymphoproliferative disorders (C-ALCL). Specific translocations have not been identified in CTCL and therefore, new strategies for detecting essential aberrant gene expression in CTCL, including miRNA expression analysis, have recently been developed [36-40].

Although to date no specific genomic translocations have been identified in CTCL, it is known that some interleukins (ILs) activate miRNAs via activation of upstream regulators of the JAK (Janus kinase)/STAT (signal transduction and activator of transcription) pathway in CTCL. The relationship between miRNAs and JAK/ STAT pathway has also recently been elucidated in the pathogenesis of CTCL. For instance, Kopp and coworkers [41] demonstrated that in SzS, IL-2 receptor $\beta \gamma(\mathrm{IL}-2 \mathrm{R} \beta \gamma) /$ JAK/STAT5 activates miR-155 up-regulation. It is known that IL-2 and IL-15 are ligands of IL-2R $\beta \gamma$. As inhibition of this pathway negatively regulates tumor cell proliferation, this pathway can be said to be oncogenic. However, that group did not show the exact target of miR-155 in SzS.

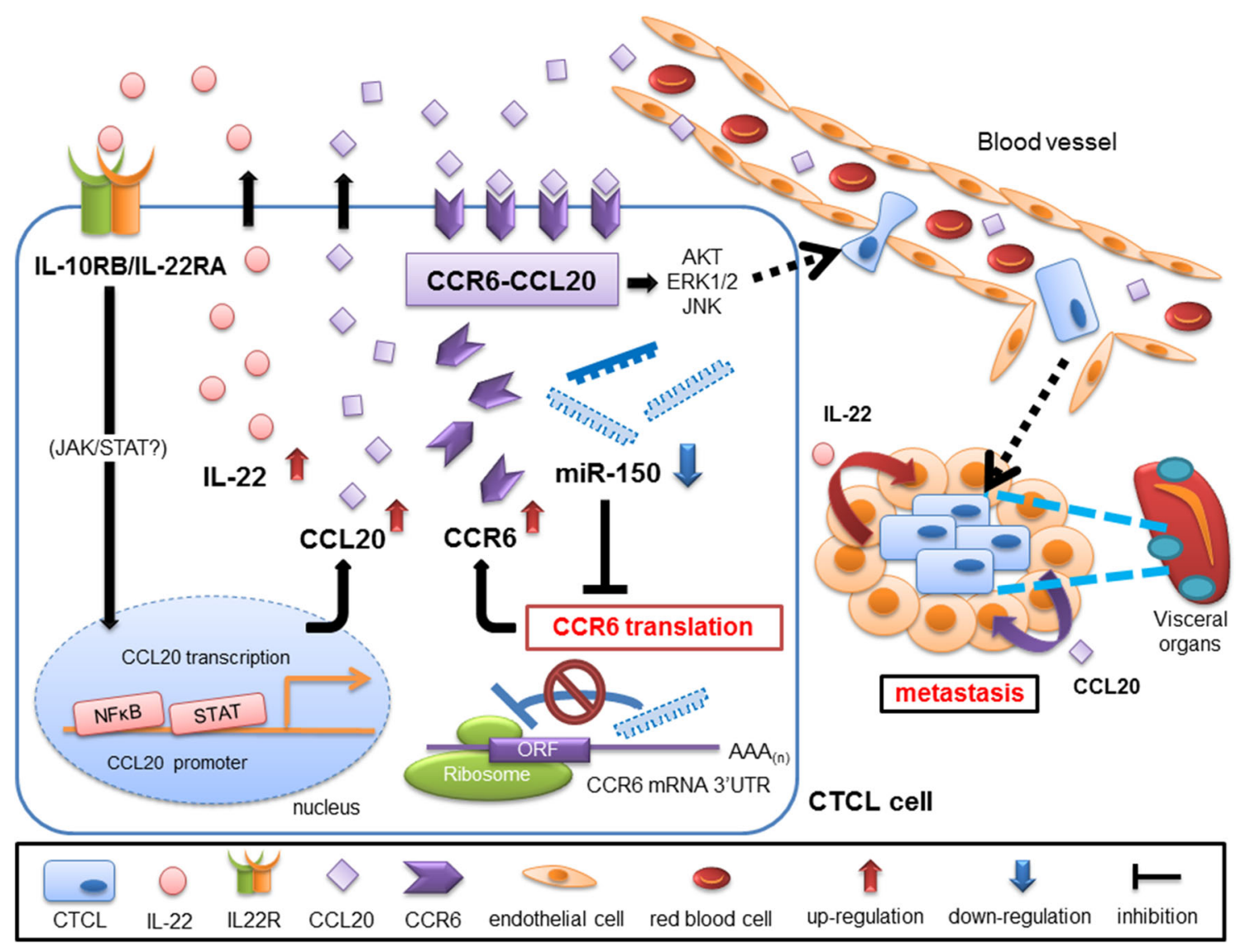

Fig. 2 Schematic illustration of invasion and metastasis of advanced CTCL. Aberrantly diminished expression of miR-150 allows advanced cutaneous T-cell lymphoma to invade multiple organs with upregulation of CCR6. MiR-150 inhibits IL-22-CCL20-CCR6 autocrine signaling in advanced cutaneous T-cell lymphoma 
Fits and coworkers [42] demonstrated that IL-21/JAK/ STAT3 is activated and STAT3 directly regulates a representative oncogenic miRNA, miR-21, in SzS. Narducci and coworkers [38] also reported that miR-21 up-regulation in CTCL has anti-apoptotic function. Qin and coworkers [43] reported up-regulation of miR-199, miR-199*, and miR-214 in the same context. As for miR-199*, Ballabio and coworkers [36] reported the detailed function of miR$199^{*}$, finding that miR-199a* combines directly with the promoter region of miR-342, which inhibits transcription of miR-342, leading to anti-apoptotic effects in CTCL cells. Our group recently found a novel target of miR-150, which is a tumor suppressive miRNA in other lymphomas [44]. MiR-150 directly down-regulates $\mathrm{C}-\mathrm{C}$ chemokine receptor type 6 (CCR6) [45]. It has been suggested that IL-22 and/or chemokine (C-C motif) ligand 20 (CCL20)/ CCR6 interaction may play an important role in the relationship between CTCL and keratinocytes or dendritic cells [46]. We further showed that (1) CTCL cells can produce IL-22 (but not IL-17), and express the IL-22 receptor, whose expression is not found in normal lymphocytes, and that (2) IL-22 stimulation against IL-22RA1 may trigger CCL20 production via activation of JAK/STAT5 pathway, leading to the enhancement of CCL20/CCR6 interaction in advanced CTCL. This interaction may enhance the migration potential of advanced CTCL, resulting in multiple invasion and metastasis of CTCL cells into various visceral organs, following a nutrition-dependent concentration gradient. As CCR6 is strictly controlled by miR150, down-regulation of miR-150 in CTCL may contribute to the constitutive activation of the IL-22/CCL20/CCR6 autocrine pathway (Fig. 2). These findings suggest that inhibition of the autocrine pathway may be therapeutically useful in advanced CTCL. Antibody for CCL20 and CCR6 could represent novel molecular targeting therapies against advanced CTCL, as well as ATLL for CCR4 [47].

Although it is important to distinguish pathological differences between skin invasive lymphomas, Lawrie's group (2012) have shown that miRNA profiling could be useful for diagnosis of C-ALCL from tumor MF or benign inflammatory dermatoses, reporting that miR-155 is highly up-regulated in C-ALCL [48]. This report suggests that miRNA profiling may be useful in distinguishing subtypes, and that information obtained about miRNA and its targets could lead us to develop new therapeutic strategies for ML.

\section{(b) Nodal PTCL}

(1) ALCL (Fig. 3): ALCL is a T-cell lymphoma with CD30 antigen expression. ALCL is a comparatively rare subtype that has been clearly defined as a single tumor entity. ALCL is classified into two subgroups, such as $\mathrm{ALK}^{+}$and ALK-negative $\left(\mathrm{ALK}^{-}\right)$type. The $\mathrm{ALK}^{+}$type occurs in younger populations than the $\mathrm{ALK}^{-}$type, while the $\mathrm{ALK}^{-}$ type occurs more frequently in older patients, and is associated with poorer prognosis [49]. A tyrosine kinase ALK was first identified in ALCL cases with $\mathrm{t}(2 ; 5)(\mathrm{p} 23 ; \mathrm{q} 35)$ chromosomal translocation [50]. ALK is located on chromosome $2 \mathrm{p} 23$, and nucleophosmin (NPM) is located on chromosome 5q35. This translocation can yield the aberrant chimeric protein NPM-ALK, leading to continuous phosphorylation of ALK, which activates
Fig. 3 STAT3-mediated miRNA alterations in $\mathrm{ALK}^{+}$ ALCL

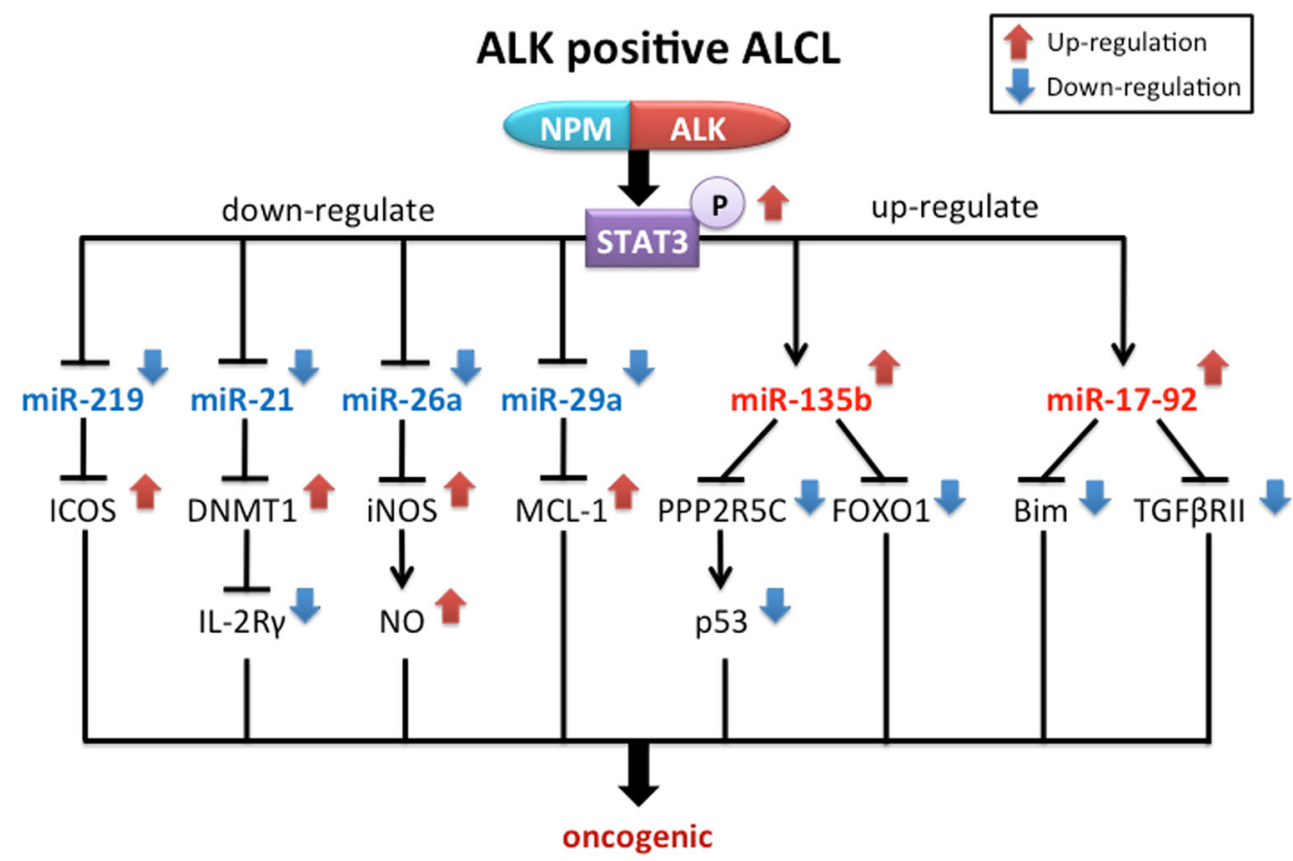


downstream signaling cascades, such as phosphoinositide 3-kinase (PI3K)/AKT and JAK/STAT [51]. The role of STAT3 in $\mathrm{ALK}^{+}$ALCL may in particular be very important in tumorigenesis [52]. Because these downstream activations are known to be enhancers of tumorigenesis, their upstream regulator, ALK, represents a possible therapeutic candidate target $[53,54]$.

In $\mathrm{ALK}^{+} \mathrm{ALCL}$, miRNA dysregulation is well documented [55, 56]. Merkel and coworkers [55] compared miRNA expression differences between $\mathrm{ALK}^{+}$and $\mathrm{ALK}^{-}$ subgroups and found several candidate miRNAs likely to be associated with tumorigenesis. They found that an oncogenic miRNA, miR-155, was frequently observed in $\mathrm{ALK}^{-}$ALCL. Moreover, they showed that the tumor-suppressive miRNA, miR-101, was commonly down-regulated in both $\mathrm{ALK}^{+}$and $\mathrm{ALK}^{-} \mathrm{ALCL}$ when compared with normal $\mathrm{CD}^{+}$cells. However, they reported that enforced expression of miR-101 led to inhibition of cell proliferation only in $\mathrm{ALK}^{+}$type. Although several oncogenic targets of miR-101, such as mTOR, MCL1, and EZH2, have been identified in various solid tumors [57-59], they concluded that mTOR signaling was the most important target of miR-101 in $\mathrm{ALK}^{+}$ALCL. Liu and coworkers recently showed that $\mathrm{ALK}^{+}$and $\mathrm{ALK}^{-}$ subtypes can be distinguished based on their distinct miR17-92 polycistron (known as the first oncomiR [60-62]) profiles; miR-17-92 polycistron was more strongly expressed in the $\mathrm{ALK}^{+}$ALCL $[56,63]$. Moreover, they found that STAT3 inhibitor (Stattic) effectively reduces miR-17-92 polycistron by use of $\mathrm{ALK}^{+}$ALCL. Otherwise, they further demonstrated the miR-135b overexpression in $\mathrm{ALK}^{+} \mathrm{ALCL}$ when compared with other peripheral T-cell lymphomas such as $\mathrm{ALK}^{-}$ALCL, AITL, and PTCL-NOS. In ALK ALCL, they demonstrated overexpression of miR-210 and other factors and down-regulation of miR-494, etc., although further functional studies are required to validate that these alterations have biological significance [56].

Activation of the transcription factor STAT3 in $\mathrm{ALK}^{+}$ ALCL is crucial and essential in the pathogenesis, as STAT3 activates or deactivates transcription and expression of various miRNA gene [64]. STAT3, which is activated by NPM-ALK, epigenetically dysregulates miRNAs, which then contribute to cancer development via alteration of downstream target genes. Recently Miyazono's group (2011) reported the role of miR-135b, which is aberrantly overexpressed in $\mathrm{ALK}^{+}$ALCL $[56,65]$. NPM-ALK activates miR-135b through STAT3 signaling; miR-135b then directly down-regulates forkhead box protein $\mathrm{O} 1$ (FOXO1), leading to enhancement of anti-tumor agent resistance. They found that miR-135b contributes to the $\mathrm{T}_{\mathrm{H}} 17$ phenotype of $\mathrm{ALK}^{+}$ALCL, as miR-135b inhibits $\mathrm{T}_{\mathrm{H}} 2$ differentiation-related transcription factors, such as STAT6 and GATA3, and up-regulates IL-17A and IL-17F expression in $\mathrm{ALK}^{+}$ALCL. They further showed that cytokines produced by $\mathrm{T}_{\mathrm{H}} 17$ cells contribute to cancer progression via induction of angiogenesis [65]. Spaccarotella and coworkers [63] found that NPM-ALK and up-regulation of STAT3 transcriptionally up-regulate miR-17-92 polycistron, which negatively regulates Bim and TGF $\beta$ receptor 2 , leading to cancer progression in $\mathrm{ALK}^{+}$ALCL. Zhang and coworkers [66] reported that NPM-ALK/STAT3 signaling inhibits miR-21 transcription and up-regulation of its target, DNA-methyltransferase 1 (DNMT1). Up-regulation of DNMT1 promotes IL-2 receptor common $\gamma$-chain DNA methylation and thus induces cancer progression by inhibition of T-cell differentiation. They also found that STAT3 down-regulates miR-219 and up-regulates inducible T-cell co-stimulator (ICOS; CD278). ICOS is defined as CD28-costimulatory receptor superfamily, and it contributes to cancer progression by initiating cell activation with TCR-CD3 complex [67]. Zhu and coworkers [68] focused on inducible nitric oxide synthase (iNOS) in the pathogenesis of ALCL. Activated STAT3 by NPM-ALK inhibits miR-26a transcription, leading to iNOS up-regulation. This up-regulation can contribute to tumorigenesis by producing a free-radical NO in the tumor cells. Desjobert and coworkers [69] showed that STAT3 inhibits miR-29a transcription, resulting in MCL1 up-regulation and enhanced anti-apoptotic activity of ALCL. Together, these reports demonstrate that the STAT3 signaling pathway is important, and that its activation contributes to the regulation of several oncomiRs, which themselves contribute to cancer progression in $\mathrm{ALK}^{+}$ALCL (Fig. 3).

Although downstream miRNA dysregulations of STAT3 are well studied, other ALK-downstream signal pathways, such as AKT, ERK and Ras, have not been reported. Independent of STAT3-related miRNA deregulation, Dejean and coworkers [70] showed angiogenesis-related miRNA; down-regulation of miR-16 activates vascular endothelial growth factor (VEGF), leading to promotion of tumor volumes via vascular endothelial growth.

As mentioned above, while there have been many studies of miRNA function in $\mathrm{ALK}^{+} \mathrm{ALCL}$; there are few such studies in $\mathrm{ALK}^{-}$ALCL. ALK ${ }^{-}$ALCL thus remains something of a "waste-box" disease. Feldman and coworkers [71] showed that relapsed $\mathrm{ALK}^{-}$ALCL recurrently represent $\mathrm{t}(6 ; 7)(\mathrm{p} 25.3 ; \mathrm{q} 32.3)$. This translocation activates miR-29a (located in $7 \mathrm{q} 32.3$ ) and down-regulation of the target, DUSP22. Because DUSP22 inhibits the TCR pathway through inactivation of ERK2 and mitogen-activated protein kinase (MAPK) [72], miR-29a activation may contribute to cancer progression. However, the miR-29 family is also known to include miRNAs that show tumor-suppressive activity in various cancers [73], making it tempting to speculate that miR-29 may have both oncogenic and tumorsuppressive roles in distinct tumor subtypes. 


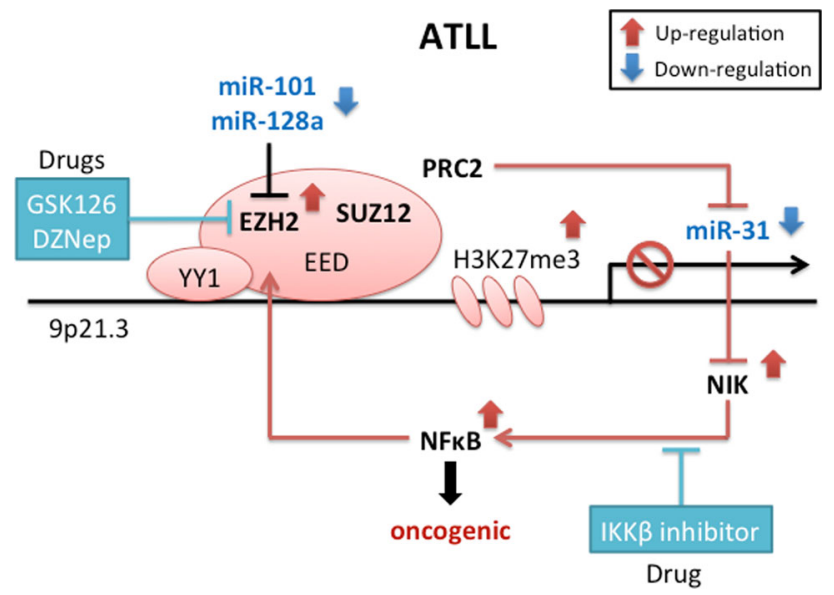

Fig. 4 PRC2/NFkB positive feedback system and association of miRNA dysregulation in ATLL

The recently developed combination of genome-wide gene expression and miRNA expression analyses has further delineated the relationship between miRNA dysregulation and STAT3 signaling. ALK inhibitors such as crizotinib against ALK-positive cancers have been developed [53,54], indicating that combination therapies using ALK inhibitors with other molecular targeting agents, including miRNA targets, may be useful in the future. It has been expected to delineate cue signal pathway, which may lead to development of new agents for ALCL therapy through discovery of miRNA-related activated signaling.

(2) ATLL (Fig. 4): ATLL is defined Human T-lymphotropic Virus-1 (HTLV-1)-infected T-cell malignancy [74]. To better understand the pathogenesis of ATLL, we should pay close attention to the concept of multistage cancer development, and the fact that this lymphoma comprises four or more subgroups, such as acute type, lymphoma type, smoldering type, and chronic types [74]. Because array-based comparative genomic hybridization (CGH) analysis previously showed distinct genomic profiles between acute and lymphoma types [75], miRNA expression pattern could be distinct in the various ATLL subtypes. Taking into account these problems, in this section we discuss miRNA dysregulation in ATLL. The first report of miRNA expression analysis of HTLV-1 infected T cell was by Bellon and coworkers [76], who conducted miRNA expression analysis to detect miRNAs associated with the development of HTLV-1 infection. They found that overexpression of miR-155 and miR-142-3p, and down-regulation of miR-125a, miR-132, and miR-181a were commonly observed in both ATLL cell lines and samples.

Recently, in ATLL or other aggressive lymphomas, the importance of the relationship between miRNA and polycomb genes [such as histone-lysine $\mathrm{N}$-methyltransferase 2 (EZH2) and B lymphoma Mo-MLV insertion region 1 homolog (BMI1)] have been reported. In ATLL (acute type), Sasaki and coworkers [77] discovered that overexpression of EZH2 and down-regulation of miR-101 and miR-128a are significantly correlated in ATLL cells derived from peripheral blood samples of ATLL patients. They suggested that activation of EZH2 and related genes might promote tumorigenesis of acute type via down-regulation of miR-101, as EZH2 and Histone H3 trimethyl Lys27 (H3K27me3) are strongly expressed in this lymphoma type as shown by immunohistochemistry assay, and because miR-101 has been demonstrated to directly regulate EZH2 [59]. Watanabe's group (2012) recently demonstrated that miR-31 is significantly down-regulated in ATLL samples (acute type). Polycomb repressive complex 2 (PRC2) (which includes EZH2) is recruited by Yin Yang 1 (YY1) to the promoter region of miR-31. This interaction induces trimethylation and transcriptional inactivation of miR-31 by H3K27me3 activation [78]. They further demonstrated that down-regulation of miR-31 directly up-regulates nuclear factor-kappa B inducing kinase (NIK), leading to activation of the NFKB pathway. This up-regulation could further activate downstream polycomb proteins, and the group suggested that a novel EZH2 inhibitor, GSK126 [79], might represent a therapeutic candidate against ATLL. Although miRNAs have been shown to play crucial roles in ATLL pathogenesis, especially in that of the acute type, miRNAs specific to ATLL subtypes, such as lymphoma type, have yet to be identified. We previously showed distinct miRNA expression patterns between lymphoma type and leukemia type of NK/T-cell leukemia/ lymphoma [80], suggesting that essential miRNAs in acute and other types might also be different. Further studies are required to distinguish among acute, lymphoma, chronic, and smoldering ATLL subtypes.

(3) PTCL-NOS: In PTCL-NOS and AITL, the deregulated non-coding RNAs include not only miRNAs (e.g., miR-768-3p), but also small nucleolar RNAs (snoRNAs) (e.g., HBII-239) [81], although the importance of miRNAs/ snoRNAs in the pathogenesis of PTCL has not been determined. Very recently, Yan and coworkers [82] demonstrated that miR-187 was overexpressed in PTCL-NOS. MiR-187 down-regulated tumor suppressor gene Disabled homolog-2 (DAB2), decreased the interaction of Dab2 with adapter protein Grb2, resulting in Ras activation, phosphorylation/activation of ERK and AKT.

\section{(c) Extranodal PTCL (e.g., ENKL)}

NK/T-cell lymphoma/leukemia can be classified into leukemic and extra nodal (ENKL) types [83]. We previously showed that up-regulation of miR-21 or miR-155, and down-regulation of miR-150, occur frequently in NK/Tcell leukemia/lymphoma $[44,80]$. Briefly, we found that 
miR-21 is up-regulated in NK-cell leukemia, and miR-155 in ENKL type. These miRNAs, respectively, regulate protein tyrosine phosphatases, Pten or Ship1, whose downregulation commonly activates AKT signaling [80]. Downregulation of miR-150 also contributes to cell proliferation and anti-aging via up-regulation of AKT2 or Dyskerin [44, $83,84]$. A previous review article by our group describes this in greater detail [14].

\section{Function of dysregulated miRNAs in Myc-expressing malignant lymphomas}

Up-regulation of the transcription factor c-Myc is frequently associated with aggressive cancer behavior. Mendell's group has shown c-Myc control transcription of multiple miRNAs [85, 86]. Therefore, the aberrant overexpression or up-regulation of c-Myc may induce aberrant up- or down-regulation of various miRNAs. For instance, c-Myc up-regulates miR-17-92 polycistron and down-regulates the miR-15a/16-1 cluster in cancer [85-87]. In B-cell lymphoma, c-Myc dysregulation is well known, and recent studies have demonstrated that miRNA dysregulations affected by c-Myc play crucial roles in B-cell lymphomagenesis. Because c-Myc is also overexpressed in aggressive T-cell lymphomas, such as $\mathrm{SzS}$ and tumor MF [88-90], c-Myc/miRNA dysregulation may also be closely associated with pathogenesis. Below, we describe miRNA dysregulation in c-Myc positive lymphoma. In aggressive B-cell lymphomas with c-Myc overexpression, such as Burkitt's lymphoma, diffuse large B-cell lymphoma, and mantle cell lymphoma, c-Myc-associated miRNAs play important pathogenetic roles. Zhang and coworkers [91] showed that c-Myc, histone deacetylase 3 (HDAC3) and $\mathrm{EZH} 2$ form a repressive complex tethered to miR-29 promoter elements to epigenetically repress miR-29 transcription in c-Myc-expressing lymphoma cells. Downregulation of miR-29 induces up-regulation of cyclindependent kinase 6 (CDK6) and insulin-like growth factor 1 receptor (IGF-1R). c-Myc regulates transcription of miR26a, the down-regulation of which leads to up-regulation of $\mathrm{EZH} 2$. This in turn reduces miR-494 expression, leading to up-regulation of c-Myc. This MYC/miR-26a/EZH2/miR494-positive feedback loop is observed in aggressive B-cell lymphomas. These findings suggest that EZH2 inhibitors may be useful for new molecular targeting therapeutic agents in c-Myc positive B-cell lymphomas. In this manner, researching miRNAs and their targets may lead to the discovery of novel key strategies against MLs, especially aggressive types. Also in T-cell lymphoma, aggressive cases in particular, c-Myc is overexpressed and associated with poor clinical outcome [88-90]. This suggests that this mechanism may occur commonly between B- and T-cell lymphomas, which show high c-Myc expression. Thus, the same therapeutic strategy may be applicable in c-Mycpositive T-cell lymphoma. Indeed, miR-187 activation could stabilize c-Myc expression in PTCL-NOS and a proteasome inhibitor, bortezomib may be useful in reducing the miR-187/c-Myc axis [83]. Furthermore, it has been recently reported that c-Myc/miR-125b-5p axis determines the sensitivity of bortezomib via modulation of Maxinteracting transcriptional repressor (MAD4) in CTCL [92]. As shown here, functional analysis of proteasome inhibitors against Myc expressing T-cell lymphomas has also been reported, and thus the advanced use of proteasome inhibitors against aggressive T-cell malignancies represents a promising future clinical strategy.

\section{Conclusion}

As we hope to have shown in this review, miRNA analysis in T-cell lymphoma/leukemias remains insufficiently understood. Nevertheless, previous reports of deep associations between miRNAs and well-defined T-cell lymphomas strongly suggest that such dysregulation may play crucial roles in undefined T-cell lymphoma subtypes as well. Notably, products that are detected as targets of miRNA may represent therapeutic molecular targets in T-cell lymphoma [e.g., inhibitor of EZH2 methyltransferase activity (GSK126) against ATLL; bortezomib against PTCL-NOS or CTCL]. Further, miRNAs or antisense miRNAs may also represent novel candidate agents for the treatment of cancer, although appropriate delivery systems have yet to be established. As miRNA plays essential roles in normal and cancer cells, we are confident that further studies promise evolutionary approaches to the treatment of aggressive lymphomas.

Acknowledgments This work was supported by JSPS KAKENHI Grant Number 25461405 [Grant-in-Aid for Scientific Research(C) (H.T)]. We wish to express our appreciation to Professor Kenichi Sawada (Akita University, Akita, Japan) for support of our experiments.

Conflict of interest The authors declare no competing financial interests.

\section{References}

1. Bartel DP. MicroRNAs: genomics, biogenesis, mechanism, and function. Cell. 2004;116:281-97.

2. Lee RC, Feinbaum RL, Ambros V. The c.elegance heterochronic gene lin-4 encodes small RNAs with antisense complementarity to lin-14. Cell. 1993;75:843-54.

3. Reinhart BJ, Slack FJ, Basson M, Pasquinelli AE, Bettinger JC, Rougvie $\mathrm{AE}$, et al. The 21-nucleotide let-7 RNA regulates developmental timing in Caenorhabditis elegance. Nature. 2000;403(6772):901-6. 
4. Lau NC, Lim LP, Weinstein EG, Bartel DP. An abundant class of tiny RNAs with probable regulatory roles in Caenorhabditis elegance. Science. 2001;294(5543):858-62.

5. Lagos-Quintana M, Rauhut R, Lendeckel W, Tuschl T. Identification of novel genes coding for small expressed RNAs. Science. 2001;294(5543):853-8.

6. Volinia S, Calin GA, Liu CG, Ambs S, Cimmino A, Petrocca F, et al. A microRNA expression signature of human solid tumors defines cancer gene targets. Proc Natl Acad Sci USA. 2006;103(7): 2257-61.

7. Calin GA, Croce CM. MicroRNA signatures in human cancers. Nat Rev Cancer. 2006;6(11):857-66.

8. Iorio MV, Croce CM. MicroRNAs in cancer: small molecules with a huge impact. J Clin Oncol. 2009;27(34):5848-56.

9. Di Leva G, Croce CM. miRNA profiling of cancer. Curr Opin Genet Dev. 2013;23:3-11.

10. Tili E, Michaille JJ, Croce CM. MicroRNAs play a central role in molecular dysfunctions linking inflammation with cancer. Immunol Rev. 2013;253(1):167-84.

11. Lawrie $\mathrm{CH}$. MicroRNAs in hematological malignancies. Blood Rev. 2013;27(3):143-54.

12. Di Lisio L, Martinez N, Montes-Moreno S, Piris-Villaespesa M, Sanchez-Beato M, Piris MA. The role of miRNAs in the pathogenesis and diagnosis of B-cell lymphomas. Blood. 2012;120(9): 1782-90.

13. Kotani A, Harnprasopwat R, Toyoshima T, Kawamata T, Tojo A. miRNAs in normal and malignant $\mathrm{B}$ cells. Int $\mathrm{J}$ Hematol. 2010;92(2):255-61.

14. Tagawa H, Ikeda S, Sawada K. Role of microRNA in the pathogenesis of malignant lymphoma. Cancer Sci. 2013;104(7): 801-9.

15. Roschewski M, Dunleavy K, Wilson WH. Diffuse large B cell lymphoma: molecular targeted therapy. Int J Hematol. 2012;96: 552-61.

16. Salles G, Ghesquières $H$. Current and future management of follicular lymphoma. Int J Hematol. 2012;96:544-51.

17. Chen CZ, Li L, Lodish HF, Bartel DP. MicroRNAs modulate hematopoietic lineage differentiation. Science. 2004;303(5654): 83-6.

18. Monticelli S, Ansel KM, Xiao C, Socci ND, Krichevsky AM, Thai TH, et al. MicroRNA profiling of the murine hematopoietic system. Genome Biol. 2005;6(8):R71.

19. Zhou B, Wang S, Mayr C, Bartel DP, Lodish HF. miR-150, a microRNA expressed in mature B and T cells, blocks early B cell development when expressed prematurely. Proc Natl Acad Sci USA. 2007;104(17):7080-5.

20. Xiao C, Calado DP, Galler G, Thai TH, Patterson HC, Wang J, et al. MiR-150 controls B cell differentiation by targeting the transcription factor c-Myb. Cell. 2007;131(1):146-59.

21. Bender TP, Kremer CS, Kraus M, Buch T, Rajewsky K. Critical functions for c-Myb at three checkpoints during thymocyte development. Nat Immunol. 2004;5(7):721-9.

22. Lieu YK, Kumar A, Pajerowski AG, Rogers TJ, Reddy EP. Requirement of c-myb in T cell development and in mature $\mathrm{T}$ cell function. Proc Natl Acad Sci USA. 2004;101(41):14853-8.

23. Ghisi M, Corradin A, Basso K, Frasson C, Serafin V, Mukherjee $\mathrm{S}$, et al. Modulation of microRNA expression in human T-cell development: targeting of NOTCH3 by miR-150. Blood. 2011;117(26):7053-62.

24. Vacca A, Felli MP, Palermo R, Di Mario G, Calce A, Di Giovine $\mathrm{M}$, et al. Notch3 and pre-TCR interaction unveils distinct NFkappaB pathways in T-cell development and leukemia. EMBO J. 2006;25(5):1000-8.

25. Li QJ, Chau J, Ebert PJ, Sylvester G, Min H, Liu G, et al. miR$181 \mathrm{a}$ is an intrinsic modulator of $\mathrm{T}$ cell sensitivity and selection. Cell. 2007;129(1):147-61.
26. Neilson JR, Zheng GX, Burge CB, Sharp PA. Dynamic regulation of miRNA expression in ordered stages of cellular development. Genes Dev. 2007;21(5):578-89.

27. Thai TH, Calado DP, Casola S, Ansel KM, Xiao C, Xue Y, et al. Regulation of the germinal center response by microRNA- 155 . Science. 2007;316(5824):604-8.

28. Rodriguez A, Vigorito E, Clare S, Warren MV, Couttet P, Soond DR, et al. Requirement of bic/microRNA-155 for normal immune function. Science. 2007;316(5824):608-11.

29. Mature T- and NK-cell neoplasms. In: Swerdlow SH, Campo E, Harris NL, Jaffe ES, Pileri SA, Stein H, et al., editors. WHO classification of tumours of haematopoietic and lymphoid tissues. Lyon: IARC Press; 2008. p.269-319.

30. Lawrie CH, Saunders NJ, Soneji S, Palazzo S, Dunlop HM, Cooper CD, et al. MicroRNA expression in lymphocyte development and malignancy. Leukemia. 2008;22(7):1440-6.

31. Navarro A, Gaya A, Martinez A, Urbano-Ispizua A, Pons A, Balagué $\mathrm{O}$, et al. MicroRNA expression profiling in classic Hodgkin lymphoma. Blood. 2008;111(5):2825-32.

32. Malumbres R, Sarosiek KA, Cubedo E, Ruiz JW, Jiang X, Gascoyne RD, et al. Differentiation stage-specific expression of microRNAs in B lymphocytes and diffuse large B-cell lymphomas. Blood. 2009;113:3754-64.

33. Suzuki HI, Mihira H, Watabe T, Sugimoto K, Miyazono K. Widespread inference of weighted microRNA-mediated gene regulation in cancer transcriptome analysis. Nucleic Acids Res. 2013;41(5):e62.

34. Suzuki HI, Matsuyama H, Noguchi M, Yao T, Komatsu N, Mano $\mathrm{H}$, et al. Computational dissection of distinct microRNA activity signatures associated with peripheral $\mathrm{T}$ cell lymphoma subtypes. Leukemia. 2013;27(10):2107-11.

35. Haynes BF, Hensley LL, Jegasothy BV. Phenotypic characterization of skin-infiltrating $\mathrm{T}$ cells in cutaneous T-cell lymphoma: comparison with benign cutaneous T-cell infiltrates. Blood. 1982;60(2):463-73.

36. Ballabio E, Mitchell T, van Kester MS, Taylor S, Dunlop HM, Chi $\mathrm{J}$, et al. MicroRNA expression in Sezary syndrome: identification, function, and diagnostic potential. Blood. 2010;116(7):1105-13.

37. van Kester MS, Ballabio E, Benner MF, Chen XH, Saunders NJ, van der Fits $\mathrm{L}$, et al. miRNA expression profiling of mycosis fungoides. Mol Oncol. 2011;5(3):273-80.

38. Narducci MG, Arcelli D, Picchio MC, Lazzeri C, Pagani E, Sampogna F, et al. MicroRNA profiling reveals that miR-21, miR486 and miR-214 are upregulated and involved in cell survival in Sézary syndrome. Cell Death Dis. 2011;2:e151.

39. Ralfkiaer U, Hagedorn PH, Bangsgaard N, Løvendorf MB, Ahler $\mathrm{CB}$, Svensson L, et al. Diagnostic microRNA profiling in cutaneous T-cell lymphoma (CTCL). Blood. 2011;118(22):5891-900.

40. Maj J, Jankowska-Konsur A, Sadakierska-Chudy A, Noga L, Reich A. Altered microRNA expression in mycosis fungoides. Br J Dermatol. 2012;166(2):331-6.

41. Kopp KL, Ralfkiaer U, Gjerdrum LM, Helvad R, Pedersen IH, Litman T, et al. STAT5-mediated expression of oncogenic miR-155 in cutaneous T-cell lymphoma. Cell Cycle. 2013;12(12):1939-47.

42. van der Fits L, van Kester MS, Qin Y, Out-Luiting JJ, Smit F, Zoutman WH, et al. MicroRNA-21 expression in CD4 $+\mathrm{T}$ cells is regulated by STAT3 and is pathologically involved in Sézary syndrome. J Invest Dermatol. 2011;131(3):762-8.

43. Qin Y, Buermans HP, van Kester MS, van der Fits L, Out-Luiting JJ, Osanto $S$, et al. Deep-sequencing analysis reveals that the miR-199a2/214 cluster within DNM3os represents the vast majority of aberrantly expressed microRNAs in Sézary syndrome. J Invest Dermatol. 2012;132(5):1520-2.

44. Watanabe A, Tagawa H, Yamashita J, Teshima K, Nara M, Iwamoto K, et al. The role of microRNA-150 as a tumor suppressor in malignant lymphoma. Leukemia. 2011;25(8):1324-34. 
45. Ito M, Teshima K, Ikeda S, Watanabe A, Nara M, Kitadate A, et al. MicroRNA-150 inhibits tumor invasion and metastasis by targeting the chemokine receptor CCR6 in advanced cutaneous T-cell lymphoma. Blood. 2014. [Epub ahead of print].

46. Miyagaki T, Sugaya M, Suga H, Kamata M, Ohmatsu H, Fujita $\mathrm{H}$, et al. IL-22, but not IL-17, dominant environment in cutaneous T-cell lymphoma. Clin Cancer Res. 2011;17(24):7529-38.

47. Ishida $\mathrm{T}$, Utsunomiya A, Iida S, Inagaki H, Takatsuka $\mathrm{Y}$, et al. Clinical significance of CCR4 expression in adult T-cell leukemia/lymphoma: its close association with skin involvement and unfavorable outcome. Clin Cancer Res. 2003;9(10):3625-34.

48. Benner MF, Ballabio E, van Kester MS, Saunders NJ, Vermeer $\mathrm{MH}$, Willemze R, et al. Primary cutaneous anaplastic large cell lymphoma shows a distinct miRNA expression profile and reveals differences from tumor-stage mycosis fungoides. Exp Dermatol. 2012;21(8):632-4.

49. Stein H, Foss HD, Dürkop H, Marafioti T, Delsol G, Pulford K, et al. CD30(+) anaplastic large cell lymphoma: a review of its histopathologic, genetic, and clinical features. Blood. 2000;96(12): 3681-95.

50. Morris SW, Kirstein MN, Valentine MB, Dittmer KG, Shapiro DN, Saltman DL, et al. Fusion of a kinase gene, ALK, to a nucleolar protein gene, NPM, in non-Hodgkin's lymphoma. Science. 1994;263(5151):1281-4.

51. Amin HM, Lai R. Pathobiology of ALK+ anaplastic large-cell lymphoma. Blood. 2007;110(7):2259-67.

52. Piva R, Agnelli L, Pellegrino E, Todoerti K, Grosso V, Tamagno I. Gene expression profiling uncovers molecular classifiers for the recognition of anaplastic large-cell lymphoma within peripheral T-cell neoplasms. J Clin Oncol. 2010;28(9):1583-90.

53. Mossé YP, Wood A, Maris JM. Inhibition of ALK signaling for cancer therapy. Clin Cancer Res. 2009;15(18):5609-14.

54. Mano H. ALKoma: a cancer subtype with a shared target. Cancer Discov. 2012;2(6):495-502.

55. Merkel O, Hamacher F, Laimer D, Sifft E, Trajanoski Z, Scheideler $\mathrm{M}$, et al. Identification of differential and functionally active miRNAs in both anaplastic lymphoma kinase (ALK)+ and ALK - anaplastic large-cell lymphoma. Proc Natl Acad Sci USA. 2010;107(37):16228-33.

56. Liu C, Iqbal J, Teruya-Feldstein J, Shen Y, Dabrowska MJ, Dybkaer $\mathrm{K}$, et al. MicroRNA expression profiling identifies molecular signatures associated with anaplastic large cell lymphoma. Blood. 2013;122(12):2083-92.

57. Wang FZ, Weber F, Croce C, Liu CG, Liao X, Pellett PE. Human cytomegalovirus infection alters the expression of cellular microRNA species that affect its replication. J Virol. 2008;82(18): 9065-74.

58. Su H, Yang JR, Xu T, Huang J, Xu L, Yuan Y, et al. MicroRNA101, down-regulated in hepatocellular carcinoma, promotes apoptosis and suppresses tumorigenicity. Cancer Res. 2009;69(3): $1135-42$.

59. Varambally S, Cao Q, Mani RS, Shankar S, Wang X, Ateeq B, et al. Genomic loss of microRNA-101 leads to overexpression of histone methyltransferase EZH2 in cancer. Science. 2008;322(5908):1695-9.

60. Ota A, Tagawa H, Karnan S, Tsuzuki S, Karpas A, Kira S, et al. Identification and characterization of a novel gene, C13orf25, as a target for 13q31-q32 amplification in malignant lymphoma. Cancer Res. 2004;64(9):3087-95.

61. He L, Thomson JM, Hemann MT, Hernando-Monge E, Mu D, et al. A microRNA polycistron as a potential human oncogene. Nature. 2005;435(7043):828-33.

62. Tagawa H, Seto M. A microRNA cluster as a target of genomic amplification in malignant lymphoma. Leukemia. 2005;19(11): 2013-6.

63. Spaccarotella E, Pellegrino E, Ferracin M, Ferreri C, Cuccuru G, Liu C, et al. STAT3-mediated activation of microRNA cluster
$17 \sim 92$ promotes proliferation and survival of ALK positive anaplastic large cell lymphoma. Haematologica. 2014;99(1): 116-24.

64. Kohanbash G, Okada H. MicroRNAs and STAT interplay. Semin Cancer Biol. 2012;22(1):70-5.

65. Matsuyama H, Suzuki HI, Nishimori H, Noguchi M, Yao T, Komatsu N, et al. miR-135b mediates NPM-ALK-driven oncogenicity and renders IL-17-producing immunophenotype to anaplastic large cell lymphoma. Blood. 2011;118(26):6881-92.

66. Zhang Q, Wang HY, Liu X, Bhutani G, Kantekure K, Wasik M. IL-2R common gamma-chain is epigenetically silenced by nucleophosphin-anaplastic lymphoma kinase (NPM-ALK) and acts as a tumor suppressor by targeting NPM-ALK. Proc Natl Acad Sci USA. 2011;108(29):11977-82.

67. Zhang Q, Wang H, Kantekure K, Paterson JC, Liu X, Schaffer A, et al. Oncogenic tyrosine kinase NPM-ALK induces expression of the growth-promoting receptor ICOS. Blood. 2011;118(11): 3062-71.

68. Zhu H, Vishwamitra D, Curry CV, Manshouri R, Diao L, Khan A, et al. NPM-ALK up-regulates iNOS expression through a STAT3/microRNA-26a-dependent mechanism. J Pathol. 2013; 230(1):82-94.

69. Desjobert C, Renalier MH, Bergalet J, Dejean E, Joseph N, Kruczynski A, et al. MiR-29a down-regulation in ALK-positive anaplastic large cell lymphomas contributes to apoptosis blockade through MCL-1 overexpression. Blood. 2011;117(24): 6627-37.

70. Dejean E, Renalier MH, Foisseau M, Agirre X, Joseph N, de Paiva GR, et al. Hypoxia-microRNA-16 downregulation induces VEGF expression in anaplastic lymphoma kinase (ALK)-positive anaplastic large-cell lymphomas. Leukemia. 2011;25(12): 1882-90.

71. Feldman AL, Dogan A, Smith DI, Law ME, Ansell SM, Johnson $\mathrm{SH}$, et al. Discovery of recurrent $\mathrm{t}(6 ; 7)(\mathrm{p} 25.3 ; \mathrm{q} 32.3)$ translocations in ALK-negative anaplastic large cell lymphomas by massively parallel genomic sequencing. Blood. 2011;117(3):915-9.

72. Alonso A, Merlo JJ, Na S, Kholod N, Jaroszewski L, Kharitonenkov A, et al. Inhibition of $\mathrm{T}$ cell antigen receptor signaling by VHR-related MKPX (VHX), a new dual specificity phosphatase related to VH1 related (VHR). J Biol Chem. 2002;277(7):5524-8.

73. Wang Y, Zhang X, Li H, Yu J, Ren X. The role of miRNA-29 family in cancer. Eur J Cell Biol. 2013;92(3):123-8.

74. Shimoyama M. Treatment of patients with adult T-cell leukemialymphoma: An overview. In: Takatsuki K, Hinuma Y, Yoshida M, editors. Advances in Adult T-Cell Leukemia and HTLV-I Research. Tokyo: Japan Scientific Societies; 1992. p. 43-56.

75. Oshiro A, Tagawa H, Ohshima K, Karube K, Uike N, Tashiro Y, et al. Identification of subtype-specific genomic alterations in aggressive adult T-cell leukemia/lymphoma. Blood. 2006;107(11): 4500-7.

76. Bellon M, Lepelletier Y, Hermine O, Nicot C. Deregulation of microRNA involved in hematopoiesis and the immune response in HTLV-I adult T-cell leukemia. Blood. 2009;113(20):4914-7.

77. Sasaki D, Imaizumi Y, Hasegawa H, Osaka A, Tsukasaki K, Choi YL, et al. Overexpression of Enhancer of zeste homolog 2 with trimethylation of lysine 27 on histone $\mathrm{H} 3$ in adult T-cell leukemia/lymphoma as a target for epigenetic therapy. Haematologica. 2011;96(5):712-9.

78. Yamagishi M, Nakano K, Miyake A, Yamochi T, Kagami Y, Tsutsumi A, et al. Polycomb-mediated loss of miR-31 activates NIK-dependent NF- $\kappa B$ pathway in adult $\mathrm{T}$ cell leukemia and other cancers. Cancer Cell. 2012;21(1):121-35.

79. McCabe MT, Ott HM, Ganji G, Korenchuk S, Thompson C, Van Aller GS, et al. EZH2 inhibition as a therapeutic strategy for lymphoma with EZH2-activating mutations. Nature. 2012; 492(7427):108-12. 
80. Yamanaka Y, Tagawa H, Takahashi N, Watanabe A, Guo YM, Iwamoto K, et al. Aberrant overexpression of microRNAs activate AKT signaling via down-regulation of tumor suppressors in natural killer-cell lymphoma/leukemia. Blood. 2009;114(15):3265-75.

81. Valleron W, Ysebaert L, Berquet L, Fataccioli V, Quelen C, Martin A, et al. Small nucleolar RNA expression profiling identifies potential prognostic markers in peripheral T-cell lymphoma. Blood. 2012;120(19):3997-4005.

82. ZX Yan, LL Wu, K Xue, QL Zhang, Y Guo, M Romer, et al. MicroRNA187 overexpression is related to tumor progression and determines sensitivity to bortezomib in peripheral T-cell lymphoma. Leukemia.2013;9. [Epub ahead of print].

83. Yamaguchi M. Current and future management of NK/T-cell lymphoma based on clinical trials. Int J Hematol. 2012;96: $562-71$.

84. He Y, Jiang X, Chen J. The role of miR-150 in normal and malignant hematopoiesis. Oncogene. 2013. [Epub ahead of print].

85. O'Donnell KA, Wentzel EA, Zelller KI, Dang CV, Mendell JT. C-Myc-regulated microRNas modulate E2F1 expression. Nature. 2005;435(7043):839-43.

86. Chang TC, Yu D, Lee YS, Wentzel EA, Arking DE, West KM, et al. Widespread microRNA repression by Myc contributes to tumorigenesis. Nat Genet. 2008;40:43-50.
87. Tagawa H, Karube K, Tsuzuki S, Ohshima K, Seto M. Synergistic action of microRNA-17 polycistron and MYC in aggressive cancer development. Cancer Sci. 2007;98(9):1482-90.

88. Qin JZ, Dummer R, Burg G, Döbbeling U. Constitutive and interleukin-7/interleukin-15 stimulated DNA binding of Myc, Jun, and novel Myc-like proteins in cutaneous T-cell lymphoma cells. Blood. 1999;93(1):260-7.

89. Vermeer MH, van Doorn R, Dijkman R, Mao X, Whittaker S, van Voorst Vader PC, et al. Novel and highly recurrent chromosomal alterations in Sézary syndrome. Cancer Res. 2008 15;68(8): 2689-98.

90. Kanavaros P, Ioannidou D, Tzardi M, Datseris G, Katsantonis J, Delidis G, et al. Mycosis fungoides: expression of C-myc p62 p53, bcl-2 and PCNA proteins and absence of association with Epstein-Barr virus. Pathol Res Pract. 1994;190(8):767-74.

91. Zhang X, Zhao X, Fiskus W, Lin J, Lwin T, Rao R, et al. Coordinated silencing of MYC-mediated miR-29 by HDAC 3 and $\mathrm{EZH} 2$ as a therapeutic target of histone modification in aggressive B-Cell lymphomas. Cancer Cell. 2012;22(4):506-23.

92. Manfè V, Biskup E, Willumsgaard A, Skov AG, Palmieri D, Gasparini $P$, et al. cMyc/miR-125b-5p signalling determines sensitivity to bortezomib in preclinical model of cutaneous T-cell lymphomas. PLoS One. 2013;8(3):e59390. 